as a whole undergoing oscillatory change of position. The observer should, with the loupe stationary, oscillate his own head to obtain parallax, the result of which is to produce successive changes in the composition of a picture whose position as a whole is unchanging.

There are various clinical conditions to the detection and examination of which contact-illumination is particularly suitable, and before enumerating those concerned with the interior of the eye, one may first dispose of those associated with the cornea.

(To be concluded.)

\title{
ANNOTATIONS
}

\section{Cataract in Ironworkers}

Some years ago the unusually great incidence of cataract in glassworkers attracted considerable attention. It was found that the cataract in its typical form was very characteristic, and the Home Office felt justified in placing it upon the schedule of diseases under the Workmen's Compensation Act. At the suggestion of Sir Clifford Allbutt they also asked the Royal Society to investigate the causation of the cataract. A committee was formed, which made observations upon the radiations to which the eyes of the workmen were exposed in the course of their duties. It was obvious that the heat factor was one which could not be ignored, and the secretary of the committee instituted an enquiry amongst ophthalmologists practising in ironworking centres to find out whether cataract was also unduly prevalent among this class of workmen. The results were entirely negative. In the following years, researches were conducted upon the absorption of various radiations by the media of the eye, among others, ultra-violet and heat radiations. Chiefly owing to the excellent research conducted by Professor A. V. Hill and Dr. H. Hartridge it became evident that the heat factor was probably of prime importance, and it became increasingly difficult to understand why certain classes of ironworkers, exposed to similar conditions so far as heat was concerned, were apparently immune. The missing link was discovered by Mr. Bernard Cridland in 1915, when he showed at the Section of Ophthalmology of the Royal Society of Medicine a case of cataract in a puddler, indistinguishable in appearance from glassworkers' cataract. Since that date Mr. Cridland has continued his investigations and has gathered together other cases in puddlers. More recently, Dr. St. Clair Roberts, of Dudley, has observed many such cases in chainmakers. Simultaneously, Dr. J. J. Healy, of Llanelly, who was already 
familiar with glassworkers' cataract among the bottlemakers of Sunderland, found the same condition in tinplate rollermen in the South Wales iron works. We are fortunate in being able to publish in this number of the Journal communications on the subject from these three gentlemen.

Additional importance is attached to the discovery because this form of cataract in ironworkers is not. scheduled under the Workmen's Compensation Act. Consequently the sufferers are placed at a disadvantage as compared with their colleagues in the glass trade. The evidence adduced by Messrs. Cridland, Roberts, and Healy is so conclusive that there is every reason to hope that the Home Office will take steps to remove this anomaly, and in the meantime the Glassworkers' Cataract Committee of the Royal Society are taking steps to this end.

\section{The Council of the Royal College of Surgeons of England}

Ophthalmic surgeons are agreed that their branch of surgery should be directly represented on the Council of the Royal College of Surgeons, and this view is, we think, shared by many of their colleagues whose professional work is less specialized. Until comparatively recent times the Council always included some surgeons who practised both general and ophthalmic surgery, who were prominent figures in the ophthalmological world and fitting representatives of ophthalmic medicine and surgery; such for example were Sir Jonathan Hutchinson and Mr. J. Whitaker Hulke, to mention only two well known members of the Council of bygone days. In later years two surgeons engaged solely in the practice of ophthalmology served on the Council ; they were Sir John Tweedy, who was elected President of the College in 1903, and Mr. Richardson Cross of Clifton. Since the latter retired in 1914, no ophthalmologist has occupied a seat on the Council, a fact which, in our opinion, is to be regretted. The recent establishment of a diploma in ophthalmic medicine and surgery by the Conjoint Board of the Royal Colleges, the question of a higher diploma in ophthalmology at the Royal College of Surgeons now under consideration, the widening interest in the education and training of those desirous of practising as ophthalmic surgeons (evidenced by the institution of the above and other examinations) all lend support to our contention.

At the forthcoming election to the Council, Mr. J. Herbert Fisher is a candidate in the interests of this special branch of surgery, and his qualifications to represent ophthalmology are beyond question. As Ophthalmic Surgeon to St. Thomas's Hospital, and formerly Dean of its Medical School, as Surgeon to the Royal London 